
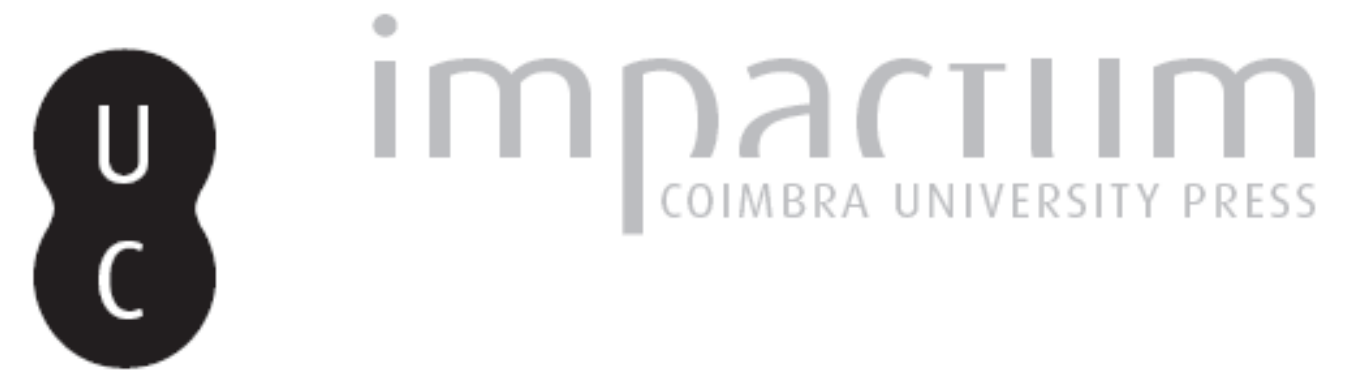

\title{
Jogos romanos de Conímbriga
}

\section{Autor(es): $\quad$ Ponte, Sálete da}

Publicado por: Imprensa da Universidade de Coimbra

URL persistente:

URI:http://hdl.handle.net/10316.2/45614

DOI:

DOI:https://dx.doi.org/10.14195/1647-8657_25_8

Accessed : $\quad$ 26-Apr-2023 13:41:57

A navegação consulta e descarregamento dos títulos inseridos nas Bibliotecas Digitais UC Digitalis, UC Pombalina e UC Impactum, pressupõem a aceitação plena e sem reservas dos Termos e Condições de Uso destas Bibliotecas Digitais, disponíveis em https://digitalis.uc.pt/pt-pt/termos.

Conforme exposto nos referidos Termos e Condições de Uso, o descarregamento de títulos de acesso restrito requer uma licença válida de autorização devendo o utilizador aceder ao(s) documento(s) a partir de um endereço de IP da instituição detentora da supramencionada licença.

Ao utilizador é apenas permitido o descarregamento para uso pessoal, pelo que o emprego do(s) título(s) descarregado(s) para outro fim, designadamente comercial, carece de autorização do respetivo autor ou editor da obra.

Na medida em que todas as obras da UC Digitalis se encontram protegidas pelo Código do Direito de Autor e Direitos Conexos e demais legislação aplicável, toda a cópia, parcial ou total, deste documento, nos casos em que é legalmente admitida, deverá conter ou fazer-se acompanhar por este aviso.

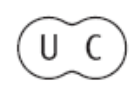


FACULDADE DE LETRAS

INSTITUTO DE ARQUEOLOGIA

CONIMBRIGA

$V O L U M E X X V$

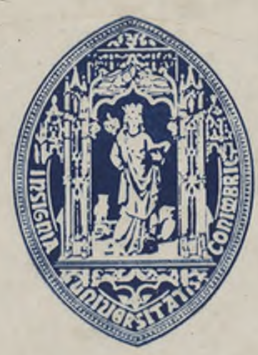

UNIVERSIDADE DE COIMBRA

1986 


\section{JOGOS ROMANOS DE CONIMBRIGA}

«Conimbriga», XNV (1986), p. 131-141

Resumo: Publicam-se, provenientes de Conimbriga, dois tabuleiros para jogos romanos, um em calcário e outro de argila: o primeiro, de forma rectangular, apresenta, numa face, o «jogo do soldado» (ludus latrunculorum) e, na outra, o «jogo das doze linhas» (duodecim scripta) ; o segundo, de forma quadrangular, destinava-se ao «jogo do moinho».

Résumé: Deux fragments de tablier de jeu provenants de niveaux d'époque romaine, à Conimbriga, sont décrits et illustrés. Le premier, en calcaire, servait, d'un côté pour le «jeu du soldat» (ludus latrunculorum) et, de l'autre, pour le jeu des «deux douze lignes» (duodecim scripta). Le second, en céramique, servait pour jouer la «marelle triple». 
(Página deixada propositadamente em branco) 


\section{JOGOS ROMANOS DE CONIMBRIGA}

0 poeta Horacio cita alguns dos jogos infantis que constituíam o encanto de novos e de velhos: «...construir casinhas, atrelar ratos a um carrinho, brincar aos pares e aos ímpares, cavalgar numa comprida cana». Estes e outros passatempos envolviam crianças e adolescentes; enquanto as crianças brincavam às casinhas (.simulacra doтиum), aos carrinhos (plostella), às bonecas (pupae), aos soldados (ducatus aut imperia), aos reis e às rainhas (judices), aos ganizes ou astrálagos (tali), os adolescentes preferiam o jogo da pela (follis), do par e ímpar (par impar), do pião (turbo), do berlinde (orea), do eixo (humeris vectare), do arco (orbis, trochus), do salto à corda e da corrida $\left({ }^{1}\right)$.

Os adultos repartiam o tempo livre pelo prazer da mesa, da leitura e do jogo. Este passatempo acompanhava o cidadão no trabalho, no passeio, no banho e no jantar. As zonas de repouso e de convívio espalhadas pela cidade eram animadas por grupos de jovens que, em silêncio ou ruidosamente, se entretinham com os jogos de azar $\left({ }^{2}\right)$ e de combinação ou de cálculo ${ }^{(3)}$. Os primeiros ${ }^{(*)}$

(*) Cf. Ugo Enrico Paoli, Vita Romana. La vie quotidienne dans la Rome Antique, Bruges, 1960, p. 359-363 (- Paoli, Vita Romana); cf. Jutta Vìtterlein, Roma ludens. Kinder und Erwachsene beim Spiel im antiken Rom, Amesterdão, 1976.

(2) Cf. O Dicionário de Jogos, Porto, 1973 (= Jogos). Este livro dá a definição de jogos de azar (p. 274): «aqueles em que o acontecimento parece não depender de modo algum das qualidades do jogador...».

(3) Cf. ibidem, p. 522 (Índice). Esta obra não define a expressão jogos de combinação, mas refere-se a ela diversas vezes, quando apresenta os jogos que nela se enquadram.

Conimbriga, 25 (1986), 131-141 
agrupavam: o jogo da moeda ou da cara/coroa [capita aut navia), astrágalos, dos dados (alae, terrerae) e da morra (micatio, digitus micare); os últimos incluíam o jogo do moinho (parva tabella lapillis), do soldado (ludus latrunculorum) e das doze linhas (duodecim scripta), que exigem o uso do tabuleiro (tabulae lusoriae).

Os jogos de azar, proibidos por lei, eram permitidos só nos «ludi saturnales» $\left({ }^{4}\right)$. Esta regra obrigatória raramente era cumprida. $\mathrm{O}$ cidadão romano secretamente jogava, quantas vezes, à mesa de jogo, a sua fortuna ou desgraçai Nos albergues (cauponae), nas tabernas, nos bares (popinae e thermopolia) e em casa, à sombra da lei, o jogo da moeda, dos dados, do par e ímpar e dos astrágalos não poupavam a bolsa dos jogadores infortunados. $\mathrm{O}$ próprio imperador Augusto, segundo o relato de Suetónio, jogava ostensivamente com amigos e convidados, ignorando a lei.

$O$ jogo da morra era, muitas vezes, tolerado nas ruas da cidade, graças à agilidade e destreza de movimentos dos jogadores. Era uma modalidade do par-ou-ímpar, porque era praticado exclusivamente com os dedos das mãos. A sorte ou infortúnio do jogador residia na adivinhação ou não do número total de dedos levantados.

Conimbriga forneceu-nos peças de jogo que ditavam, pelo golpe de sorte $\left(^{5}\right)$, o jogador a quem caberia o início da partida: o jogo da moeda $\left({ }^{6}\right)$, dos dados e dos astrágalos $\left({ }^{7}\right)$. Essa sorte era ditada pelo valor simbólico das moedas ou pelo valor numérico de cada uma das faces dos dados ou dos astrágalos.

Os dados e os astrágalos serviam ainda para o jogo do par-ou-

(4) Cf. Paoli, Vita Romana, p. 363; cf. Jérôme Carcopino, A vida quotidiana em Rom,a no apogeu do Império, Lisboa, 1938, ed. «Livros do Brasil», n. ${ }^{\circ}$ 5, p. 304 (= CARCOPINo, Vida quotidiana).

$\left.{ }^{5}\right)$ Chama-se golpe de sorte ao primeiro lance do dado (moeda, dado ou astrágalo) quando indica o maior valor numérico.

$\left({ }^{6}\right)$ Cf. Isabel Pereira, Jean-Pierre Bost, Jean Hiernard, Fouilles de Conimbriga, III, Res monnaies, Paris, 1974 (= Fouilles de Conimbriga, III), p. 6, Est. I, n.os 1 a 5 .

$\left(^{7}\right.$ Cf. A. Moutinho Alarcão e Sálete da Ponte, Colecções do Museu Monográfico de Conimbriga. Catálogo, Coimbra, 1984 (= Catálogo), p. 79-80, hg. 1. 
-ímpar $\left(^{8}\right)$. Os astrágalos pertenciam, também, ao foro dos mais novos, quando o praticavam como mero passatempo.

Jogava-se com quatro astrágalos $\left({ }^{9}\right)$. Eram ossículos de animais (carneiro e ovelha) com quatro faces irregulares: a face lisa simbolizava a imagem da morte (deus Anubis/Kyon) e valia um ponto correspondente ao as $\backslash$ a face oposta ao cão (Kyon) era consagrada a Vénus e equivalia a 6; a face côncava valia 3 , e a convexa, 4 pontos. A melhor jogada era a de Vénus $(1,3,4,6)$, correspondente a 14 pontos. Os quatro astrágalos permitiam trinta e cinco combinações $\left({ }^{10}\right)$. Este jogo era tão do agrado do imperador Augusto que o praticava com os seus parceiros em qualquer momento $\left({ }^{n}\right)$; outras vezes oferecia, no seu próprio palácio, aos membros da sua família, 250 dinheiros por cabeça para que «...pudessem entregar-se ao jogo sem preocupações e sem pensamentos reservados...»(12).

Hoje em dia, o jogo dos astrágalos ou das cinco pedrinhas obedece a outras regras bem mais simples. Reside na destreza manual dos jogadores quando pretendem apanhar o maior número de «pedrinhas» com as costas da mão esquerda $\left({ }^{13}\right)$.

O jogo da moeda servia para dar início a qualquer partida. Os jogadores escolhiam caput aut navia (cabeça ou navio), o que corresponde, actualmente, à expressão cara ou coroa $\left({ }^{14}\right)$. As moedas mais antigas (15) tinham numa face a cabeça bifronte do deus Jano; na outra, a proa de um navio. O nome de caput aut navia

$\left.{ }^{8}\right)$ Os jogadores procuravam adivinhar o número de objectos (moedas, nozes, etc.) encerrados na mão direita do adversário. No caso de acertar no número de objectos contidos na mão direita, o jogador retirava ao adversário uma peça de jogo.

$\left.{ }^{9}\right)$ Cf. Jogos, p. 17 e p. 155-158. Este passatempo é designado também por jogo dos ganizes e do cucarne.

(10) Cf. ibidem, p. 157.

(u) Cf. Anita RIECHE, so Spielten die Alten Ròmer. Rõmische Spiele im archàologischen Park Xanten, Koln, 1984, «Glucksspiele» ( = RIECHE, Alten Ròmer).

(12) Cf. Carcopino, Vida quotidiana, p. 305 e 365.

(13) Cf. Jogos, p. 158 (Cucarne).

(u) Cf. ibidem, p. 154 (cruzes ou cunhos) e p. 105 (caras ou coroas).

$\left({ }^{15}\right)$ Cf. Fouilles de Conimbriga, III, Est. I, n. os 1 a 5. 
manteve-se, mesmo depois do desaparecimento deste tipo monetário.

Os jogos de tabuleiro eram passatempo de combinação e de cálculo bem mais complexos. Incluíam o jogo das doze linhas, o jogo do soldado e o jogo do moinho. Exigiam dos jogadores destreza intelectual, raciocínio, inteligência, sentido de decisão, espírito de análise e previsão de lances combinados.

Adolescentes e adultos dedicavam largo tempo dos seus ócios a estes passatempos, tanto em casa, como nas ruas da cidade ou na taberna. Encontravam, umas vezes, tabuleiros de jogos gravados nas lajes do forum e das termas da cidade; outras vezes, os tabuleiros improvisados eram traçados no solo, gravados nas lajes, incisos em placas de tijolo $\left({ }^{16}\right)$.

Em Conímbriga encontraram-se, a par de numerosas peças de jogo $\left({ }^{17}\right.$ ), dois tabuleiros de jogo, um dos quais é duplo (duodecim scripta e ludus latrunculorum), ocupando cada uma das faces da placa calcária (Figs. 1-2); o outro (parva tabella lapillis) preenche uma das faces de um pequeno tijolo quadrangular (Fig. 3).

\section{Jogo das doze linhas (Fig. 1-2)}

Este jogo, praticado com frequência pelos Gregos, foi posteriormente adoptado pelo Romanos com o nome de duodecim scripta ou ludus XII scriptorum. É, segundo parece, o prototipo do triquetraque ou gamão praticado nos nossos dias. São necessários dois jogadores, cada um com doze ou quinze pedras (pretas e brancas), um copo (terricula ou fritillus) com dois ou três dados e um tabuleiro (alveolus) rectangular $\left({ }^{18}\right)$.

(16) Cf. Carcopino, Vida quotidiana, p. 306; J. P. V. D. Balsdon, Life and leisure in ancient Rome, Londres, 1969, p. 158 (Basilica Julia no Forum, Roma); M. Bendala GALÁn, Tablas de juego en Italica, «Habis», Sevilha, 1973, n. ${ }^{\circ}$ 4, p. 263-272.

(17) Cf. Jorge Alarcão, Robert étienne, Adília Moutinho Alarcáo e Sálete da Ponte, Fouilles de Conimbriga, VII, Trouvailles Diverses - Conclusions Générales, Paris, 1979, p. 180-181, Est. XLIX, 206-217; Catálogo, p. $79-80$, fig. 1 , n. ${ }^{\text {os }} 376,378$ a 381 (p. 84-85).

(18) Cf. Jogos (Triquetraque), p. 466-467. 
O tabuleiro de jogo poderia ser móvel ou fixo, feito de argila, de mármore ou de calcário. Comportava vinte e quatro casas divididas por doze linhas verticais cortadas transversalmente por duas secantes paralelas.

As casas ou alvéolos eram numeradas de I a XXIV no sentido contrário ao dos ponteiros do relógio (da $1 .^{\text {a }}$ casa do canto superior direito para a $12 .^{a}$ casa do canto esquerdo, passando pela $13 .^{a}$ casa do canto inferior esquerdo, até á última casa, ou seja, á $24 .^{\mathrm{a}}$ casa do canto direito).

Os jogadores colocavam-se um em frente do outro, tendo de permeio o tabuleiro. Muniam-se de doze ou quinze pedras, brancas e pretas, para depois iniciarem a partida. Colocavam no início do jogo as pedras na fila do meio, «pontos de partida», ou seja, no espaço não riscado do tabuleiro.

À abertura do jogo era ditada pelos dados. O jogador que obtivesse no primeiro lanço o maior número de pontos começava a partida. O jogador lançava os dados (dois ou três) e podia escolher entre movimentar uma só pedra ou avançar duas ou três numa só jogada: uma, correspondente ao número total de pontos marcados pelos dados; duas ou três pedras, segundo o número de pontos marcados em cada dado. As pedras eram movimentadas para casas abertas, isto é, quando não ocupadas, pelo menos, por duas pedras de outra cor.

Uma pedra sozinha numa casa podia ser expulsa por uma adversária e recolocada no «ponto de partida», quando os dados forneciam um número de pontos correspondente ao da casa ocupada por uma pedra de outra cor. Uma casa podia ser ocupada por duas ou mais pedras da mesma cor, considerando-se «fechada» às do adversário. $\mathrm{O}$ jogador teria direito a mais do que um lançamento, desde que ambos os dados marcassem dois números iguais.

A partida seria ganha pelo jogador que passasse todas as suas pedras para a 1. a casa, ou seja, para o «ponto de partida».

As regras de jogo do gamão são, hoje em dia, muito semelhantes às do jogo das doze linhas. As maiores diferenças residem na numeração e colocação das pedras no início do jogo. As casas são actualmente numeradas a partir do canto inferior esquerdo, passando pela $12 .^{a}$ casa do canto inferior direito, de seguida pela $13 .^{\mathrm{a}}$ 
casa do canto superior direito até à $24 .^{\mathrm{a}}$ casa do canto superior esquerdo. As pedras são colocadas no começo da partida na primeira casa.

\section{Jogo do soldado (Fig. 3-4)}

O jogo do soldado era conhecido pelo jogo dos latrúnculos, nome que os Romanos davam às fichas de jogo (latrunculi ou latrones). O escritor Varrão chamava latruncules aos guarda-costas do príncipe. Era, por assim dizer, um nome de guerra (19). $\mathrm{Na}$ época arcaica, latro significava «soldado mercenário», enquanto que na época de Cícero passou a designar vagabundo ou ladrão. É assim que as peças passavam a chamar-se milites ou bellatores ${ }^{(20)}$. Era considerado um jogo de estratégia militar, em que o tabuleiro simbolizava o campo de batalha $\left({ }^{21}\right)$; as pedras de jogo eram as hostes militares que, em linha, procuravam passar ao terreno do adversário e «comer» ou expulsar um ou mais soldados isolados. As pedras de jogo que chegassem à última fila do tabuleiro formavam dama (mandrae). Este jogo era popular nos finais da República e durante o Império.

$\mathrm{O}$ tabuleiro, às vezes feito de materiais preciosos $(22)$, era, noutros casos, traçado no solo pelos próprios jogadores. Cada jogador necessitava de um tabuleiro quadrangular com 64 casas e de 16 pedras (pretas e brancas). As pedras de jogo eram de dois tamanhos: as pequenas eram as ordinárias (calculi ordinarii) e as maiores, as errantes \{calculi vagi). As pedras de jogo eram, no início da partida, colocadas nas duas primeiras filas horizontais do tabuleiro. As ordinárias (espécie de peões do xadrez), colocadas na segunda fila, avançavam na vertical de

(19) Cf. ibidem (latrunculos), p. 308-309.

(20) Cf. PAOLI, Vita Romana, p. 364.

(21) Cf. Jogos (latrunculos), p. 309. O poeta Saleio Basso refere-se ao jogo dos latrunculos como um combate entre dois exércitos inimigos.

(22) Cf. M. Ch. Daremberg et Edm. Saglio, Dictionnaire des Antiquités Grecques et Romaines, Paris, 1902 (2. a parte), L-M, p. 1403. 
casa em casa, enquanto que as errantes na primeira fila deslocavam-se em todas as direcções. Uma pedra (ordinária ou errante) saltava por cima da do adversário, ocupava a casa livre e retirava-a do jogo. A mesma poderia continuar a «comer» sucessivas pedras do adversário se, entre elas, houvesse casa livre. Os arqueólogos e os historiadores encontraram sempre grandes dificuldades na reconstituição fiel da estrutura do jogo do soldado. Há investigadores que o aproximam do jogo de xadrez; outros, porém, reconhecem-lhe afinidade com o jogo das damas.

Ambos os jogos de tabuleiro (duodecim scripta e ludus latrunculorum) eram muito populares na época romana. Confirmam-no os testemunhos arqueológicos recolhidos em diversos sitios romanos $\left.i^{23}\right)$.

O jogo do soldado era, no entanto, o divertimento mais generalizado entre os cidadãos romanos. É curioso observar que, no noroeste peninsular, mormente na Galiza $\left({ }^{24}\right)$, há tabuleiros gravados em pedra e que se assemelham ao jogo do soldado.

1. Fragmento de tabuleiro (Figs. 1-4). Calcário de Ançã.

Inv. 66.68. Dimensões: 95x125x40 mm.

Placa dividida em ambas as faces por linhas incisas, formando, num dos lados, quadrados (ludus latrunculorum) e, no outro, colunas (duodecim scripta) $\left({ }^{25}\right)$.

\section{Jogo do moinho (Fig. 5-6)}

O jogo do moinho inclui-se no vasto grupo de tabulae lusoriae. Estes tabuleiros eram quadrangulares (de forma quadrada ou rectangular) ou circulares; estes últimos constituíam uma moda-

(23) Cf. Christian und Claudia Holliger, Rõmischc Spielsteine und Brettspiele, «Jahresbericht der Gesellschaft Pro Vindonissa», Brugg, 1984, p. 5-23 (jogo do soldado de Mainz (p. 19) e jogo das doze linhas de Auton (p. 20).

${ }^{24}$ Cf. Fernando Javier Costas Goberna e outros, Petroglifos del litoral sur de la ría de Vigo, "Quiñones de León»(Cástrelos), Vigo, 1984, n. ${ }^{\circ}$, p. 27 (Ra-Bayomallosa, Santa Catarina) e p. 258 («Os poziños» em Villaza-Gondomar).

(25) Cf. Catálogo, p. 84. A face correspondente ao tabuleiro duodecim scripta foi posteriormente reaproveitada. Os dois traços paralelos são bem visíveis. 
lidade do jogo do* moinho. a 0 círculo era dividido por quatro perpendiculares que se entrecruzavam e formavam oito quadrantes. Os restantes modelos eram divididos por duas perpendiculares que uniam, num centro comum, os três quadrados ou rectángulos inscritos (26).

$\mathrm{O}$ jogo do moinho circular caiu em desuso, permanecendo o quadrangular. Esta última modalidade era, para os gregos e romanos, um jogo de cálculo bastante popular. Gravavam-no em lugares públicos, traçavam-no no chão térreo ou desenhavam-no em tijolos não totalmente secos, como no exemplar de Conímbriga (Fig. 5). Gravuras idênticas encontram-se também no Noroeste peninsular, nomeadamente na Galiza $\left({ }^{27}\right)$. Em Portugal, conhecemos o mesmo motivo geométrico gravado no castelo novo de Idanha-a-Nova, na capela românica de S. Miguel da Serra de Monsanto $\left({ }^{28}\right)$, em Longroiva ${ }^{(29)}$, no templo romano de Évora $\left.{ }^{(30}\right)$ e no Monte da Cegonha (Yidigueira) $\left.{ }^{(31}\right)$.

A representação de tabuleiros de jogo em monumentos históricos testemunha a ocupação dos operários da obra durante o descanso ou o reaproveitamento de antigos elementos de construção. A origem deste jogo remonta, segundo o erudito E. Four-

(26) Cf. Rieche, Alten Rõmer (ficha n. ${ }^{\circ} 18$ ).

(27) Cf. Fernando Javier Costas Goberna e Julio Fernandez Pintos, Diseños quadrangulares a modo de tableros de juegos en los petroglifos del Noroeste de la Peninsula Ibérica, "Arqueologia», Pontevedra, 1986, n. ${ }^{\circ} 2$ (no prelo). São exemplares do Monte Lobeira e do Castro de Xián.

(28) Cf. Francisco henriques, Carlos Caninas e António henriques, Levantamento de algumas gravações antigas sobre rocha do Sul da Beira Interior, «Beira Alta», Viseu, 1982, vol. XLI, fase. 3, p. 705-712 (p. 706-707).

(29) Tabuleiro gravado num bloco granítico e achado junto do castelo, actualmente depositado na Junta de Freguesia. O tabuleiro com o jogo do moinho tem as seguintes dimensões: $40 \times 30 \mathrm{cms}$. Estes elementos foram cedidos gentilmente pelo cónego António Pereira Amante, de Longroiva.

$\left.{ }^{(30}\right)$ Tabuleiro gravado numa das pedras graníticas do templo, do lado esquerdo da frontaria. Informação dada pelo dr. Bairrão Oleiro, ao qual estamos gratos.

(31) Escavações efectuadas por Conceição Lopes e Rafael Alfenim. O tabuleiro está gravado num tijolo rectangular incompleto com as dimensões de 160X150 mm. Tem a referência AI18(3). 
nier, aos Fenicios, que «para onde quer que iam, levavam essa imagem, verdadeiro e simbólico estandarte do seu poderio» $\left({ }^{32}\right)$.

Este jogo necessitava de dois parceiros, um tabuleiro quadrangular (portátil ou fixo) e dezoito pedras (brancas e pretas). $\mathrm{O}$ tabuleiro de jogo constava de três quadrados ou rectángulos interligados ou não por meio de duas perpendiculares, formando doze ou dezasseis linhas que agrupavam vinte e quatro pontos. Cada linha comportava três pontos que formavam o «moinho», quando ocupados por pedras da mesma cor. No início da partida, os jogadores escolhiam a cor das pedras (pretas ou brancas); em seguida, distribuíam-nas alternadamente em cada um dos pontos do tabuleiro. O jogador, tanto na colocação ou distribuição como na movimentação das pedras, procurava formar ou «fechar» um moinho. O jogador, por cada moinho que completasse, retirava ao seu adversário uma pedra que não pertencesse a um moinho já feito. Colocadas as nove pedras, o jogador movimentava-as para qualquer ponto mais próximo, até formar um moinho (simples ou duplo) e poder retirar uma pedra adversária. Obtinha-se um «moinho duplo», quando cinco pedras da mesma cor ocupavam dois lados contínuos do mesmo quadrado ou rectángulo inscrito, ou quando as cinco pedras preenchiam os cinco pontos de intercepção das duas perpendiculares com os quatro lados da figura quadrangular mais pequena.

$\mathrm{O}$ jogador que tivesse somente três pedras em jogo podia saltar e colocar-se em qualquer ponto livre; somente com duas pedras, perdia a partida.

Este jogo aparece, nos nossos dias, associado ao jogo das damas ou ao jogo do xadrez, publicitando nomes de fábricas ou de laboratórios. As regras do jogo romano mantiveram-se até hoje, inalteráveis.

2. Tabuleiro quase completo (Figs. 5-6). Argila. Inv. 68.4. Dimensões: 124X120X40 mm. Tijolo com uma das faces marcada por três rectángulos incisos, interligados por meio de duas perpendiculares formando dezasseis linhas que comportam vinte e quatro pontos. Cada linha contém três pontos.

(32) Cf. Jogos (Marelles), p. 334-335. 


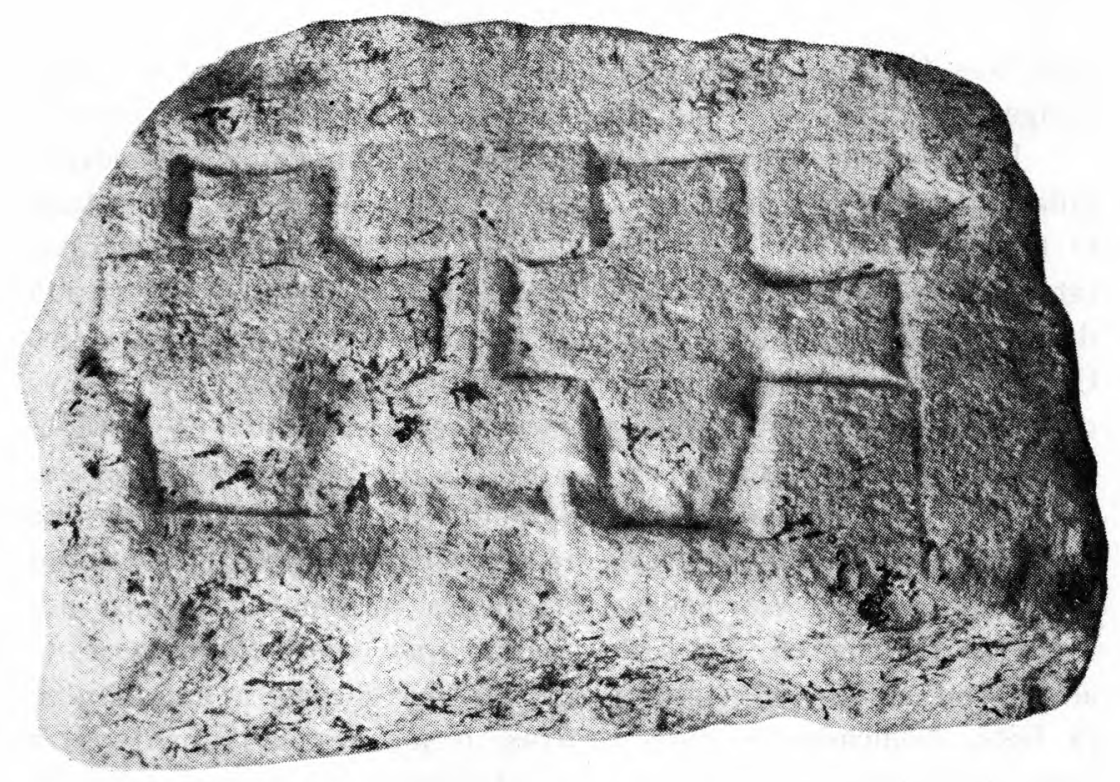

FIG. 1

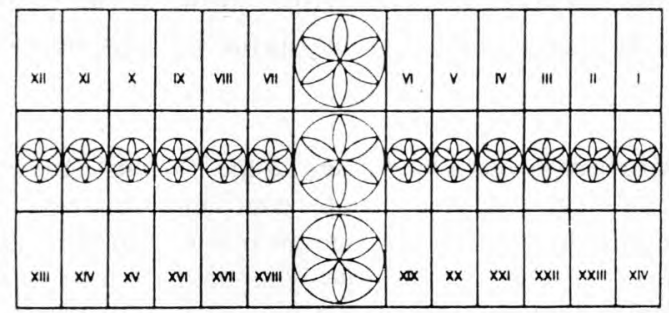

FIG. 2 


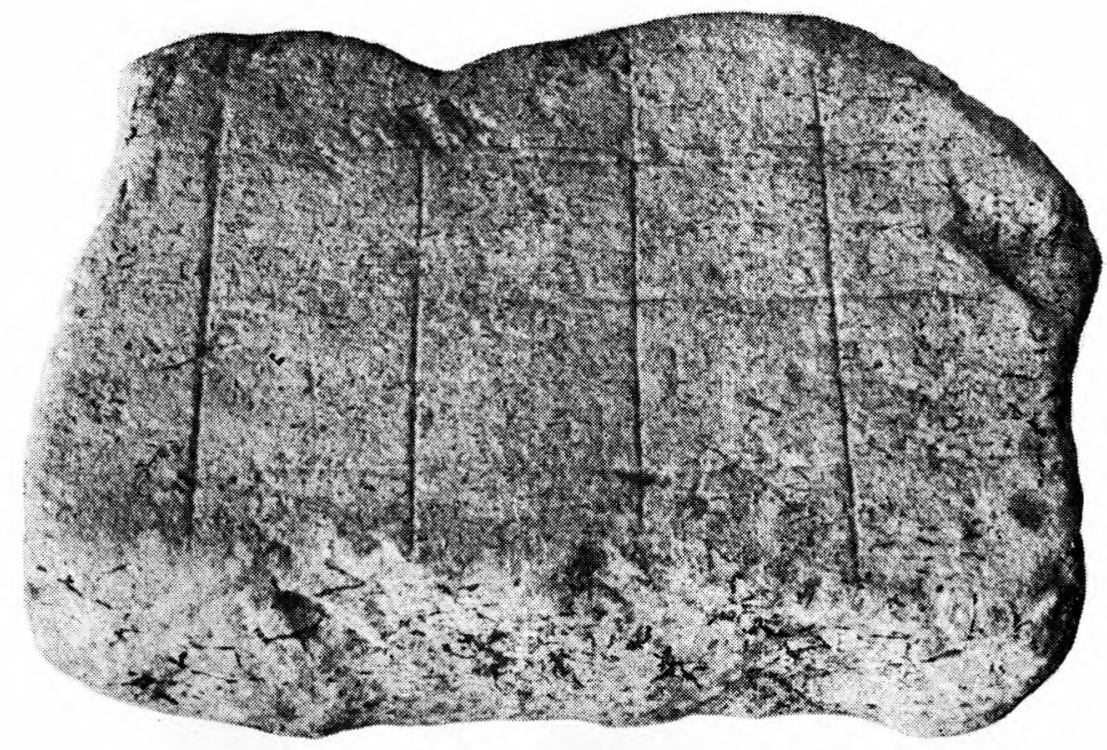

FIg. 3

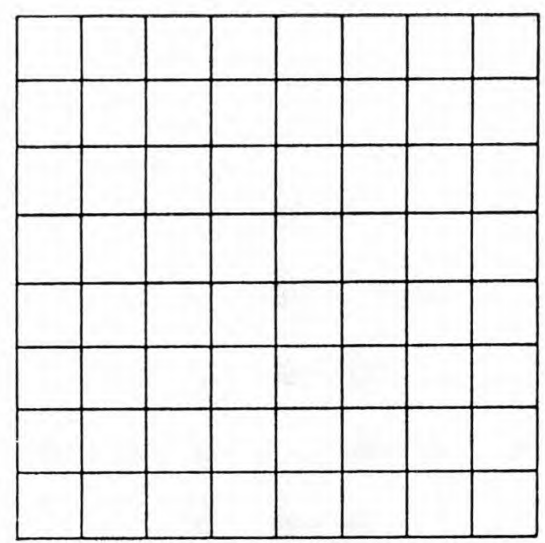

FIG. 4 


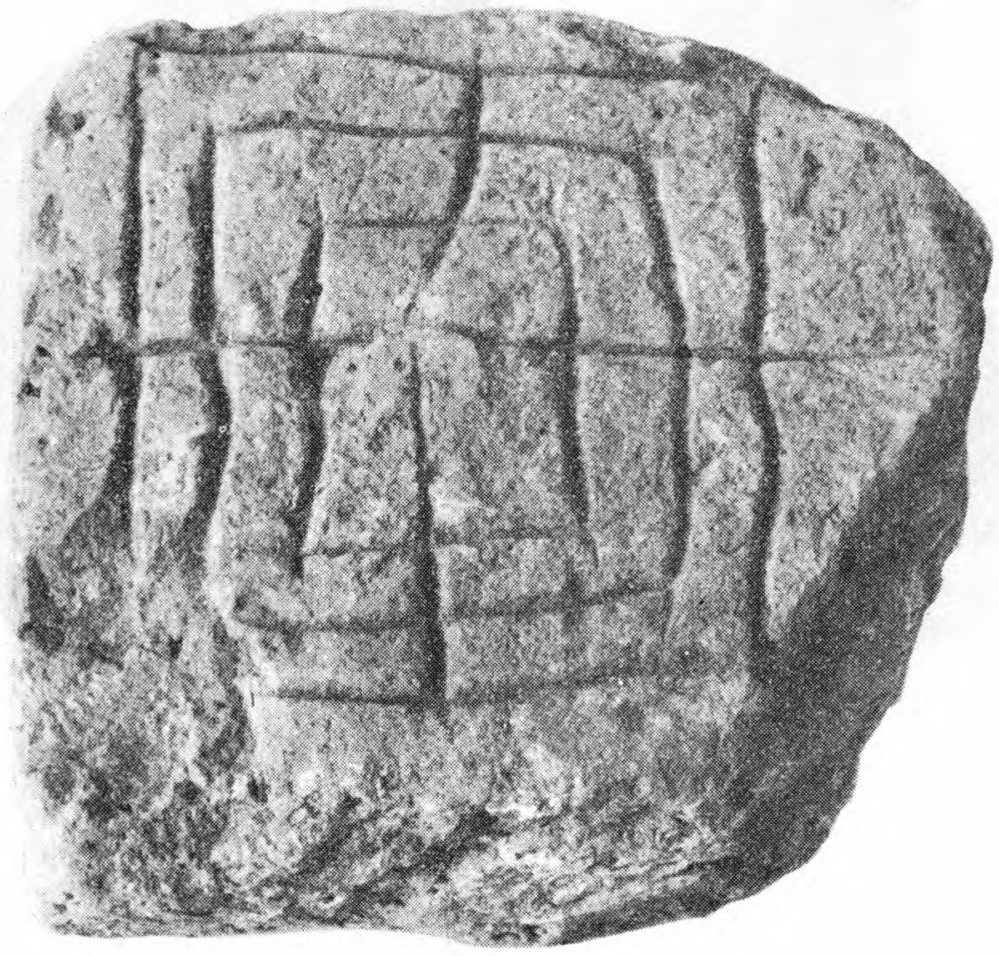

FIG. 5

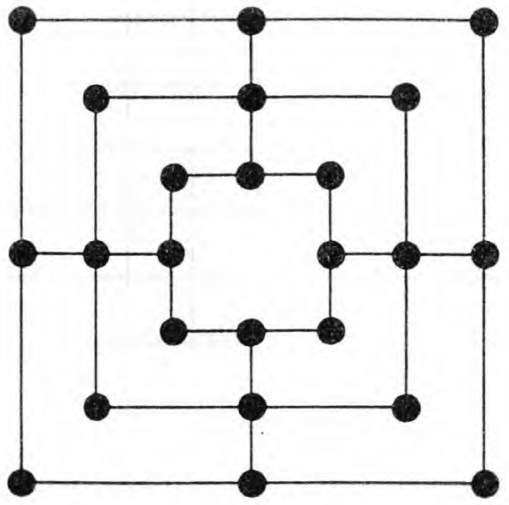

FIG, 6 